\title{
OPTIMAL ALLOCATION OF BISCUIT INGREDIENT IN THE PRODUCTION PROCESS - AN INVARIANT PROPERTY BASED ALGORITHM APPROACH
}

\author{
Ekere S. Udofia* \\ Department of Mathematics and Statistics, Akwa Ibom State University, Ikot Akpaden, Mkpat Enin, Akwa \\ Ibom State, Nigeria \\ Idorenyin A. Etukudo \\ Department of Mathematics and Statistics, Akwa Ibom State University, Ikot Akpaden, Mkpat Enin, Akwa \\ Ibom State, Nigeria
}

\begin{abstract}
:
For the achievement of optimal ingredient allocation and mixing, this work proposes a mathematical model of efficient allocation of these ingredients. The problem of this allocation in the production of biscuit is modeled as a linear programming problem and analyzed using an invariant property based algorithm approach. An Optdesolver, a computer program was used to obtain the optimal solution to this problem. This solution revealed that in order to have a maximum profit of $\$ 3,404,010.27$, the allocations to shortcake, petit, marie and gem should respectively be $\$ 270.50, \$ 267.50, \$ 268.20$ and $\$ 268.80$.
\end{abstract}

Keywords: Biscuit, Optimal Allocation, Production Process, Invariant, Approach.

DOI: $10.7176 /$ MTM/9-4-06

Publication date: April $30^{\text {th }} 2019$.

\subsection{INTRODUCTION}

The word 'biscuit' means different things to different people. In America, the word describes a chemically leavened (baking powder) bread-type product, the nearest equivalent in New Zealand being a scone. Products known as biscuit in the United Kingdom are called cookies and crackers in the USA.

In France, Switzeland and Italy, a great quantity of simple plain biscuit are made by larger manufacturers. Many varieties are also made by bakers. Biscuit which require more work and a degree of decoration are referred to as 'Petit'.

Biscuit differ from other baked cereal products such as bread and cakes by having low moisture content. Bread typically has $35-45 \%$ moisture; Cake has $15-30 \%$ moisture and biscuit has 1- 5\% moisture. This low moisture content ensures that biscuit are generally free from microbiological spoilage and can be stored for a long time ( long shelf life) if they are protected from absorbing moisture from damped surrounding or atmosphere. Biscuits have relatively high energy density compare with other baked goods. Many travellers and explorers over the centuries have been grateful to biscuit for these properties. [1]

Biscuit are oven-baked food items with greater nutritive value than plain bread of equal weight. The country's requirement of biscuit is met through local production and importation. The demand is estimated at 1.02 million tons, the demand for the next five years is projected to reach 1.15 million tons and 1.32 million tons in the next ten years.

Biscuit are classified as hard, soft and batter. They can be savory, sweet, plain-baked, filled or coated or a mixture of several of these options. Some biscuit satisfy special dietary needs such as those for high fiber, protein or extra vitamins. If packed in a moisture proof material, biscuit can have a long shelf life. [2] 
The principal raw materials required are wheat or maize flour chocolate, petite, sugar, salt, baking powder, manila flavor, lemon and water.

\section{INGREDIENTS}

As mentioned earlier, The principal(main) ingredient used for biscuit manufacture are wheat flour, fat and sugar, water which is present in flour at about $14 \%$ by weight of sample (that is $14 \%$ of the flour is water). Water is also required at dough mixing process along with other ingredient such as sugar syrups, but these are largely removed during the baking process. Water does play an important role in biscuit making.

The structure and the texture of the biscuit are determined by the ingredients, mixing, forming and the baking process. The wheat flour is composed of carbohydrate, (as starch), protein and fat, together with some fiber ash and trace minerals and vitamins.

Typical specification in wheat flour is extraction $85 \%$, moisture content $14 \%-15 \%$ [3]

\begin{tabular}{|l|l|l|l|}
\hline Property & Soft Flour \% & Medium Flour \% & Strong Flour \% \\
\hline Protein & 8.0 & 10.3 & 13.2 \\
\hline Wet gluten & & 26.0 & 31.0 \\
\hline Fat & & 1.0 & 2.4 \\
\hline carbohydrate & & 76.3 & 66.9 \\
\hline Ash & 0.3 & 0.5 & 0.5 \\
\hline Water absorption & 53.0 & 58.0 & 60.0 \\
\hline
\end{tabular}

Most biscuit are made with soft or weak flour, strong flours which are ideal for yeast raise products such as bread, tend to bind up mixture and not allow the Oven spread which desirable in most biscuit types.

\section{BISCUIT BAKING PROCESS}

In baking good quality biscuits, the starting point is the understanding of the ingredients and the baking process. Wheat flour along with other ingredients is mixed with water and dough is prepared. Then it is kept at normal temperature for about couple of hours to allow proper fermentation. Then it is placed on the biscuit molding trays and these trays are placed in oven for baking. After the requisite baking, trays are then taken out cooled and biscuit are packed. [4] 


\section{STAGES OF BISCUIT BAKING PROCESS}

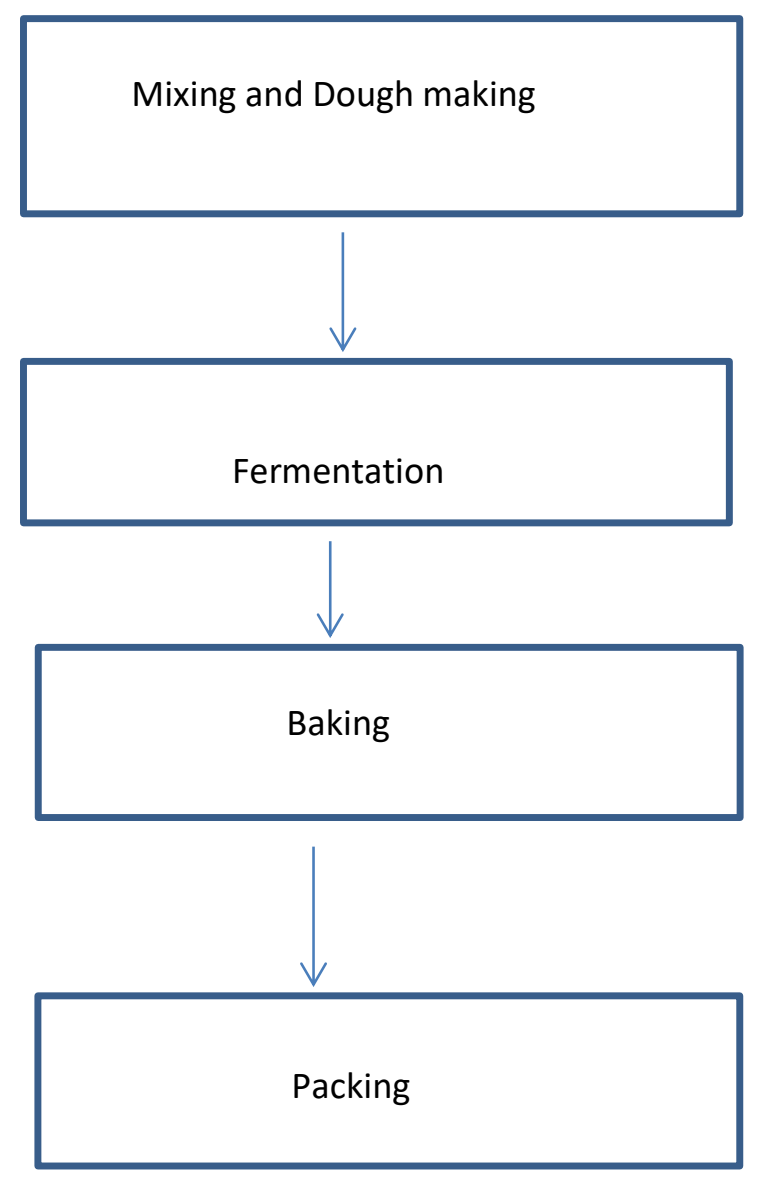

We shall look at these under the following outlines.

\section{(a) From dough piece to biscuit}

There are three (3) main changes that shall be observed when biscuit is being baked. They are:

(i) The development of the biscuit structure and texture

(ii) The reduction in the moisture content

(iii) The development of the colour

These overlap during baking process, but it is useful to note that the formation of the structure and texture of the biscuit will take in the first half of the biscuit baking oven, the reduction in moisture mainly in the middle of the oven and the colour in the final third of the oven.

\section{Biscuit structure}

For a high quality biscuit, the following characteristics are important.

Texture: the texture is open and flaky

Density/Volume: Low density gives more volume and lighter bite.

Bite/Mouth feel: Crispiness, softness

Flavor: many flavours and fillings are heat susceptible and the protection of the flavours texture of the filling need to be considered for the baking process. 


\section{Moisture content}

Important factors in baking dough with high water content such as crackers and water biscuit, low moisture content enhances the keeping quality of the biscuits. Evenness of the moisture content from the center to the outside of the biscuit requires penetrative heat and adequate time for baking and cooling to avoid 'checking' cracks in the biscuit after packing.

\section{Colour}

Consistency of colour with time and across the width of the oven band, some products such as Marie require a very even blend colour others such as cream crackers and some rotary molded designs require colour contrast and highlights.

These features require different baking systems to enhance the appearance of the product.

There are many complex physical and chemical changes from the dough piece to biscuit during baking. These changes are mainly temperature and time dependent and occur at different stages during baking, though they may overlap and interact. The specification of the bakery system should be based primarily on the product(s) to be made and their requirement in terms of structure, texture, density, bite, flavor and colour. The characteristics of the biscuit will determine the type of heat transfer which is appropriate at each stage of the baking process. This will define the oven specification, the appropriate heat ratings and the zone lengths. [5], [6]

Mustafa Ozilgen and J.R Heil, Modeled the drying behavior of a single baking biscuit using unsteady state, anisotropic, two dimensional, simultaneous heat and mass balances. Solution of these equations agreed well with the experimentally determined temperature and the moisture data. Model revealed that the outer section of the baking biscuit conduction and diffusion were the dominant heat and mass transfer mechanisms, respectively. In the central section of the biscuit the gas cells cracked with the increased vapor pressure and the upward volume expansion. Then air/vapor enclaves were formed among the horizontal dough layers in the radial direction. The dominant heat and mass transfer mechanisms in the central section of the biscuit were convection. Presence of two different regime zones in a baking biscuit may have important consequences concerning the strength of the commercial products against crumbling marketing and consumption [7]

This work showcased the knowledge gained on the process-to-product interaction in the continuous tunnel oven. The work covers development of new experimental equipment for pilot plant baking experiment, a mathematical model of heat and mass transfer in a butter cookie product and evaluation of quality assessment method. A mathematical model describing the heat and mass transfer in butter cookie during baking was successfully formulated. The model was solved numerically by the use of a finite element method. Model optimization and validation was successfully carried out against experimental data obtained in the new pilot plant oven. The effect of the baking tray on mass transfer was examined through comparison of different modeling set- ups and experimental data. It was found that while the baking tray was likely to reduce evaporation from the bottom surface, it is not correct to assume that no evaporation takes place at the covered surface.

Parallel to the construction of the pilot oven, and advanced multi-spectral imaging method was investigated as a method for quality as assessment of butter cookies. The ability of the method to assess multiple quality aspect from one image was the main focus of the study. The system was able to predict both the surface browning and the water content in butter cookies [13].

Due to globalization, many manufacturers encounter tight competition in the market place, consumers can find goods with cheaper prices, better quality and faster delivery, consequently production time and quality is increasingly important for competitiveness. Research has focus on production problems with constant processing time and non- deteriorated item, however in many real industrial applications, processing time and values of product may change due to deterioration and wear phenomena such as decay, damage, spoilage, evaporation, etc. that result in decreasing usefulness. The process control and reset for deteriorating processes are challenging for production, production planning should be adjusted according to the time control process to meet the production target.

Proper production planning can considerably improve a producer's competitiveness in delivering low-cost products with high quality and short-cycle time. In a deterioration process, the quality may change during a production run, leading to early product failures. To mitigate the impact of deterioration such as process shifting, the optimal resetting cycle before the next setup must be determined as well as the initial settings of the beginning of a production run. The work by [14] was aimed at proposing a mathematical model that consists of a 
new quality-loss function and adds maintenance cost to the ordering inventory holding cost commonly considered in the classical model. The model was applied to a real world case study to demonstrate the effect of initial settings of the mean quality characteristics. The result demonstrated the superiority of the proposed approach in terms of total production cost, as compared with the economic production quantity model.

RIV Biscuit Company Nigeria Ltd Port Harcourt produces four products (shortcake, Petit, Marie, Gem) using 9 (nine) raw materials [8]

For the achievement of optimal ingredient allocation and mixing, this paper proposes a mathematical model of efficient allocation of these ingredients. The problem of these ingredients allocation is modeled as a Linear Programming Problem and analyzed using the solution technique called the invariant property based algorithm (IPBA) developed by [9]

\subsection{STRUCTURE OF LINEAR PROGRAMMING MODEL}

The matrix structure of linear programming problem takes the form

$\operatorname{Max} .(\operatorname{or} \operatorname{Min}) f(\underline{X})=\underline{C^{T}} \underline{X}$

Subject to:

\section{$\underline{A} \underline{X} \quad(\leq,=, \geq) \quad \underline{b}$}

$\underline{X} \geq 0$

Where $f(\underline{X})$ is the objective function.

The row matrix $\underline{C^{T}}=\left(c_{1}, c_{2}, c_{3}, \ldots, c_{n}\right)$ is the gradient of the objective function.

$\underline{A} \underline{X} \quad(\leq,=, \geq) \quad \underline{b} \quad$ are functional constraints and

$\underline{X} \geq 0$ are non-negativity constraints

([10], [11], [8],[12])

\subsection{METHODOLOGY}

The sequential procedure for the IPBA as given by [9] are:

Initialization Step: Initial design matrix.

Choose an initial design matrix, $\mathrm{X}$ from a response surface such that

$$
2(\mathrm{n}+1) \leq \mathrm{N} \leq \mathrm{n}(\mathrm{n}+1)+2
$$

Where $\mathrm{n}=$ number of decision variables and $\mathrm{N}=$ number of support points, chosen in such a way that the constraints are not violated.

Step 1: Optimal starting point.

Use the initial design matrix to determine the optimal starting point, $\mathbf{x}_{\mathbf{1}}^{*}$.

Step 2: Direction of movement.

Select $\mathbf{d}=\mathbf{c}$ where $\mathbf{d}=$ direction vector and $\mathbf{c}=\left(\mathrm{c}_{1}, \mathrm{c}_{2}, \ldots, \mathrm{c}_{\mathrm{n}}\right)$ is the gradient of the objective function. By normalizing $\mathbf{d}$, we obtain $\mathbf{d}^{*}$.

Step 3: Determine the optimal step length, $\rho_{1}^{*}$

For a maximization problem, use 


$$
\rho_{1}^{*}=\rho_{1 i}^{*}=\max _{i}\left\{\frac{\mathbf{A}_{\mathbf{i}} \mathbf{x}_{\mathbf{1}}^{*}-b_{i}}{\mathbf{A}_{\mathbf{i}} \mathbf{d}^{*}}\right\}
$$

and for a minimization problem, use

$$
\rho_{1}^{*}=\rho_{1 i}^{*}=\min _{i}\left\{\frac{\mathbf{A}_{\mathbf{i}} \mathbf{x}_{\mathbf{1}}^{*}-\mathrm{b}_{\mathrm{i}}}{\mathbf{A}_{\mathbf{i}} \mathbf{d}^{*}}\right\}
$$

where $\mathbf{A}_{\mathbf{i}} \mathbf{x}=\mathrm{b}_{\mathrm{i}}, \mathrm{i}=1,2, \ldots, \mathrm{m}$ is the ith constraint of the linear programming problem.

Step 4: First movement

Make a move to the point

$$
\mathbf{x}_{2}^{*}=\mathbf{x}_{1}^{*}-\rho_{1}^{*} \mathbf{d}^{*}
$$

Step 5: Termination criteria

(a) Compute $\mathrm{f}\left(\mathbf{x}_{2}^{*}\right)$ and $\mathrm{f}\left(\mathbf{x}_{\mathbf{1}}^{*}\right)$.

(b) If $\left|\mathrm{f}\left(\mathbf{x}_{\mathbf{2}}^{*}\right)-\mathrm{f}\left(\mathbf{x}_{\mathbf{1}}^{*}\right)\right|<\varepsilon$ where $\varepsilon=0.0001$, the algorithm terminates. If not, replace $\mathbf{x}_{\mathbf{1}}^{*}$ by $\mathbf{x}_{\mathbf{2}}^{*}$ and determine a new step length using the constraint that gave the optimum step length in step 3 . If the new step length, $\rho_{2}^{*}$ $=0$, then the optimizer had earlier been located in step 4 .

\subsection{DEVELOPMENT OF LINEAR PROGRAMMING MODEL FOR EFFECTIVE ALLOCATION OF BISCUIT RAW MATERIALS FOR OPTIMAL PRODUCTION.}

The decision variables are

$$
\begin{aligned}
& x_{1}=\text { amount allocated for Shortcake } \\
& x_{2}=\text { amount allocated for Petit } \\
& x_{3}=\text { amount allocated for Marie } \\
& x_{4}=\text { amount allocated for Gem }
\end{aligned}
$$

The table below is the hypothetical data for raw material allocation of Riv Biscuits Company Nigeria Limited.

TABLE 1.1 RAW MATERIAL ALLOCATIONS IN RIV BISCUITS COMPANY NIGERIA LIMITED.

\begin{tabular}{|l|l|l|l|l|l|l|}
\hline & Raw Materials & Short cake & Petit & Marie & Gem & $\begin{array}{l}\text { Maximum } \\
\text { available in a } \\
\text { month }\end{array}$ \\
\hline 1 & Flour $(\mathrm{kg})$ & 200 & 200 & 200 & 200 & 215000 \\
\hline 2 & Sugar $(\mathrm{kg})$ & 40 & 24 & 24 & 23 & 50000 \\
\hline 3 & Oil (liter) & 44 & 14 & 14 & 14 & 45000 \\
\hline 4 & Salt (kg) & 2 & 2 & 2 & 2 & 2500 \\
\hline 5 & Baking Powder $(\mathrm{kg})$ & 0 & 0.2 & 0.2 & 0.3 & 500 \\
\hline 6 & Petit & 0 & 1.2 & 0 & 0 & 1000 \\
\hline 7 & Marie & 0 & 0 & 1.2 & 0 & 800 \\
\hline 8 & Lemon & 0 & 0 & 0 & 1.2 & 1000 \\
\hline 9 & Chocolate & 1.2 & 0 & 0 & 0 & 1000 \\
\hline
\end{tabular}

Since the objective function is profit, the contribution of each product to profit is obtained as follows: 
TABLE 2.1

\begin{tabular}{|l|l|l|l|}
\hline Product & Selling Price & Cost of Production & Contribution to Profit \\
\hline Short Cake & 13,830 & 10,050 & 3,780 \\
\hline Petit & 10,440 & 7,650 & 2,790 \\
\hline Marie & 13,000 & 10,000 & 3,000 \\
\hline Gem & 13,260 & 10,170 & 3,090 \\
\hline
\end{tabular}

We obtain a linear optimization model for the production of products of Riv Biscuits Company Nigeria Limited to maximize gross profit, assuming that the company sells all it produces. We have the following linear programming problem (LPP) model from the above tables.

$$
\text { Maximize } f(\underline{x})=3780 x_{1}+2790 x_{2}+3000 x_{3}+3090 x_{4}
$$

Subject to the following raw material constraints

$$
\begin{aligned}
200 x_{1}+200 x_{2}+200 x_{3}+200 x_{4} & \leq 215000 \\
40 x_{1}+24 x_{2}+24 x_{3}+23 x_{4} & \leq 50000 \\
44 x_{1}+14 x_{2}+14 x_{3}+14 x_{4} & \leq 45000 \\
2 x_{1}+2 x_{2}+2 x_{3}+2 x_{4} & \leq 2500 \\
0 x_{1}+0.2 x_{2}+0.2 x_{3}+0.3 x_{4} & \leq 500 \\
0 x_{1}+1.2 x_{2}+0 x_{3}+0 x_{4} & \leq 1000 \\
0 x_{1}+0 x_{2}+1.2 x_{3}+0 x_{4} & \leq 800 \\
0 x_{1}+0 x_{2}+0 x_{3}+1.2 x_{4} & \leq 1000 \\
1.2 x_{1}+0 x_{2}+0 x_{3}+0 x_{4} & \leq 1000 \\
x_{1}, \quad x_{2}, x_{3}, x_{4} & \geq 0
\end{aligned}
$$

\subsection{ANALYSIS OR SOLUTION OF THE ABOVE LPP MODEL BY IPBA}

By using optdesolver, a software developed for solving problems of this nature by this method, we have the results as shown below:

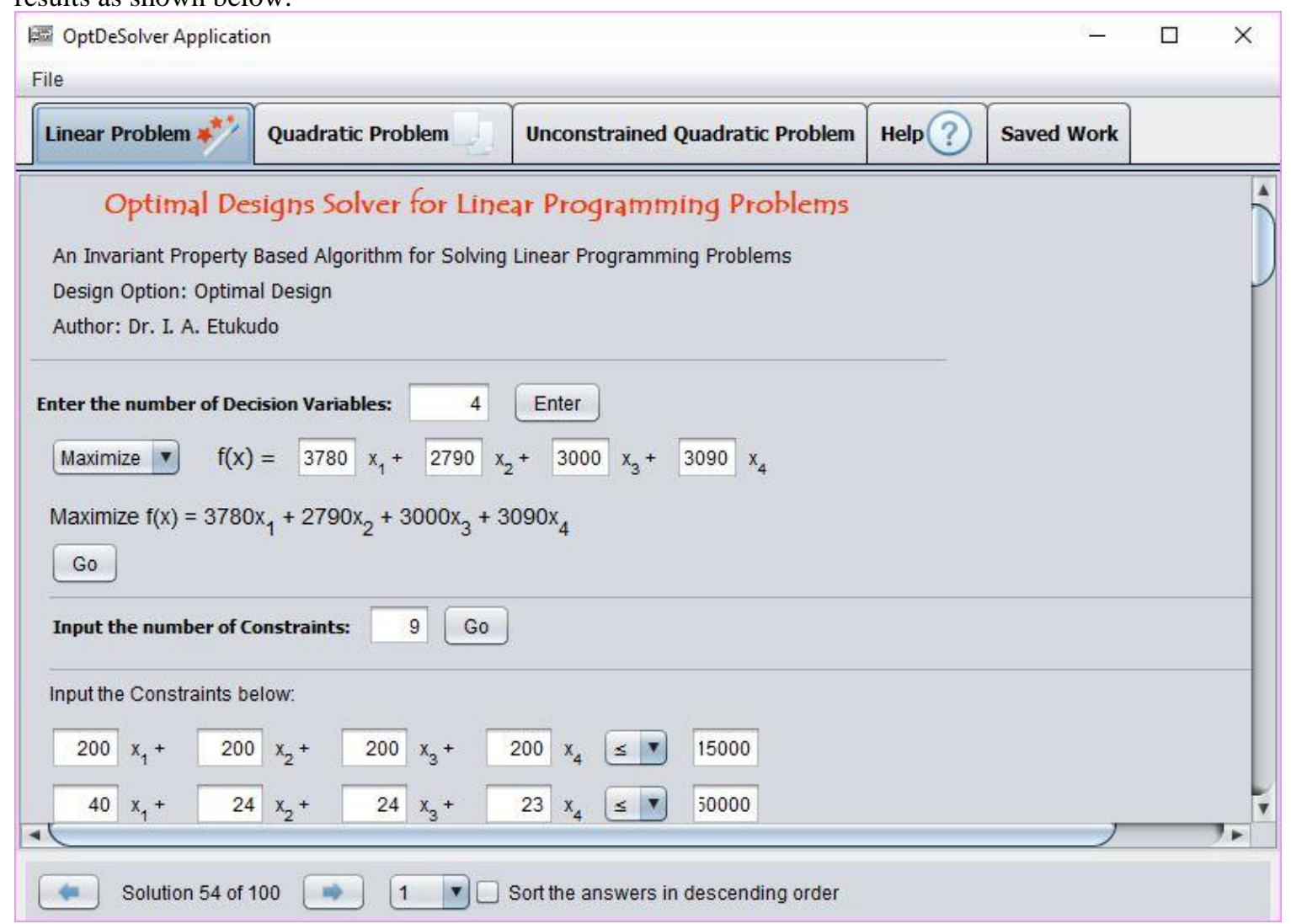




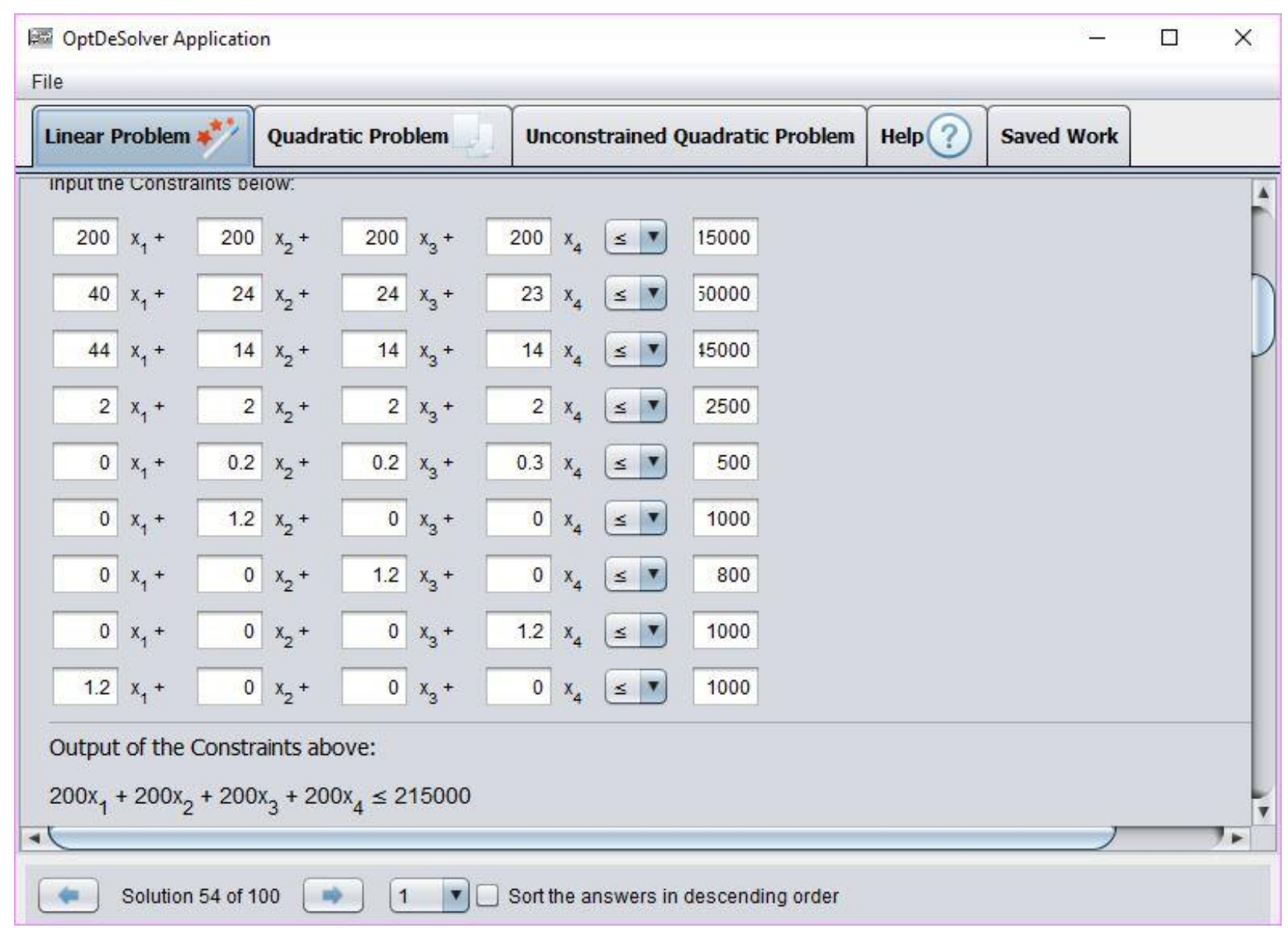

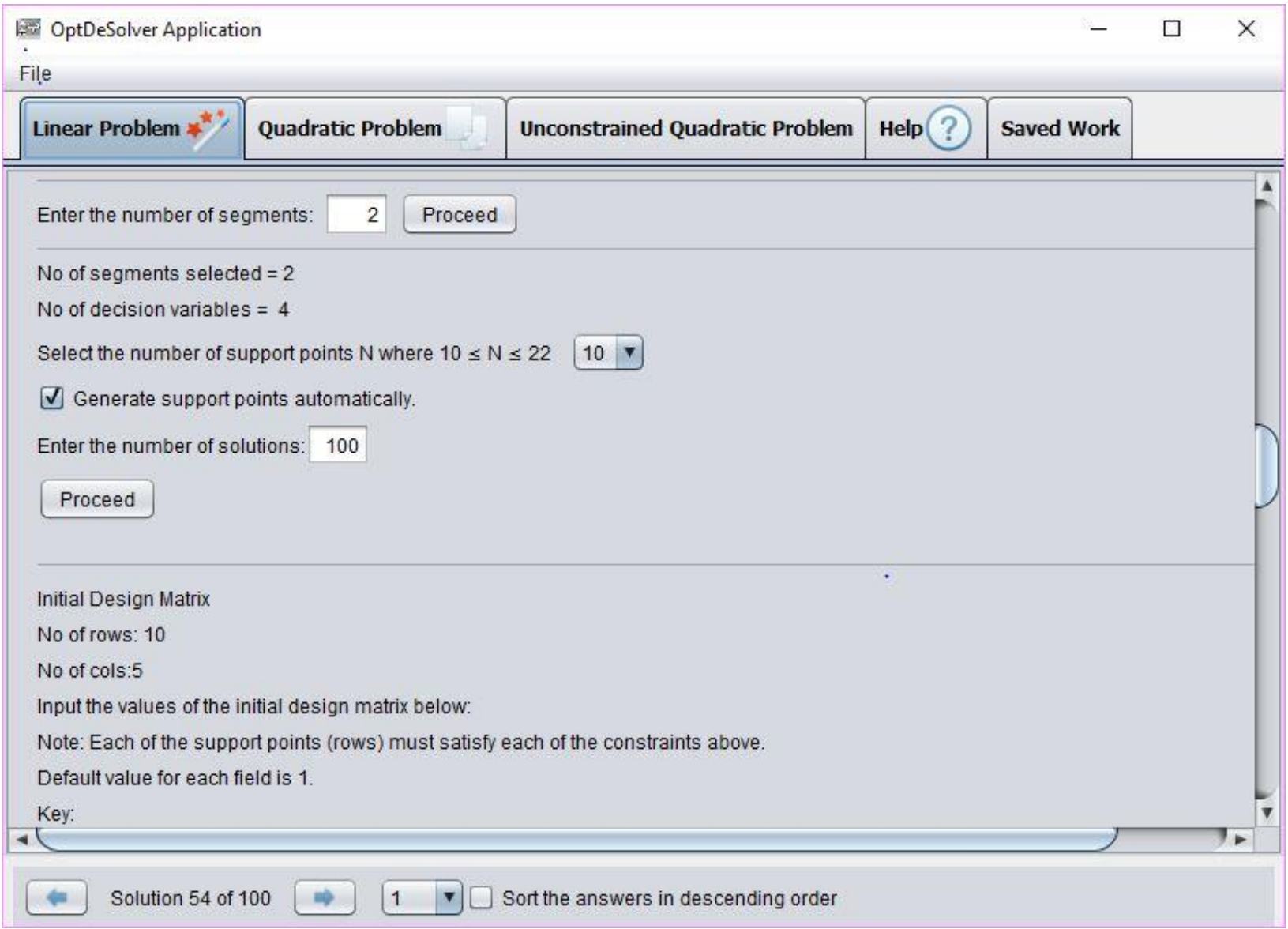



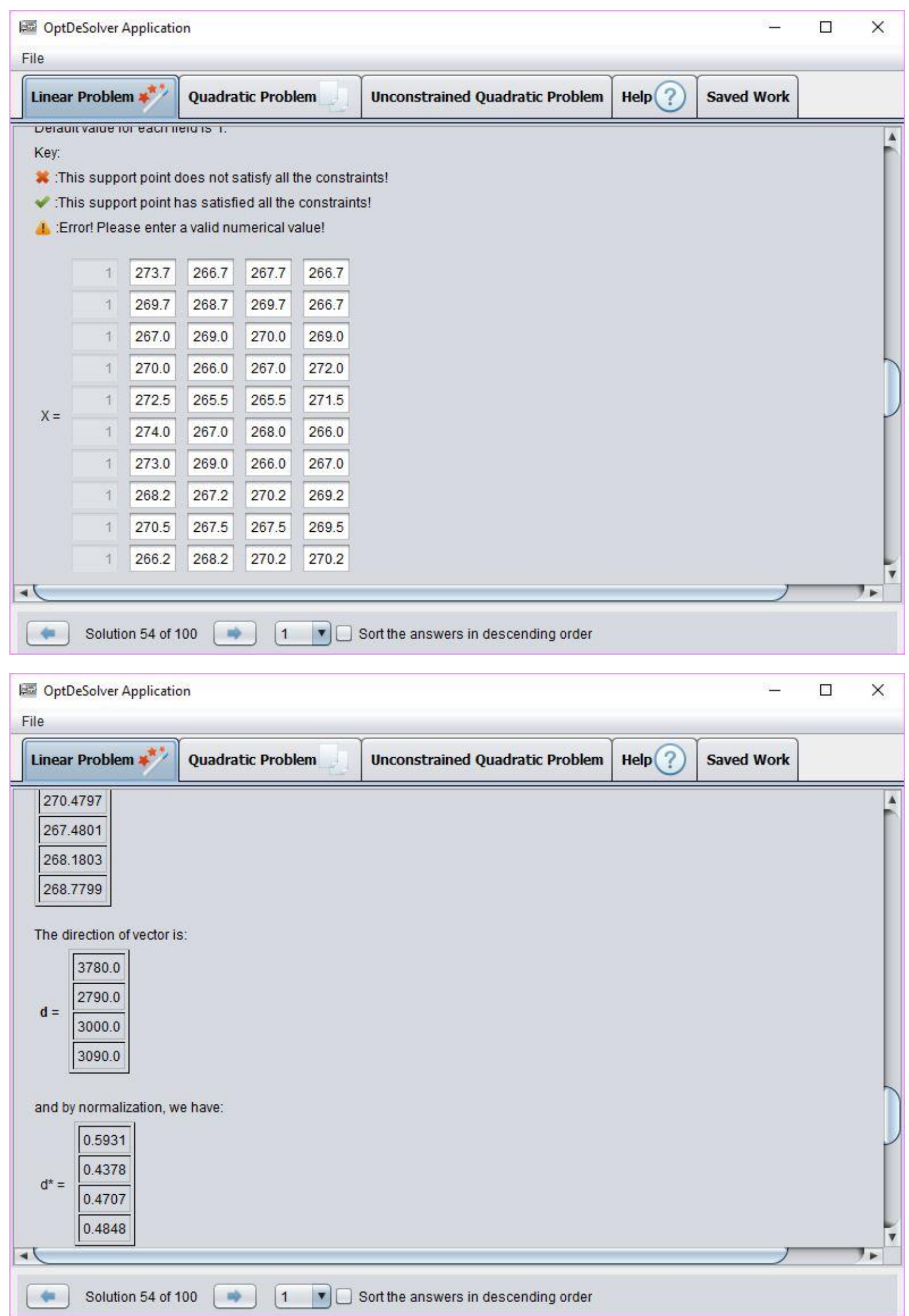


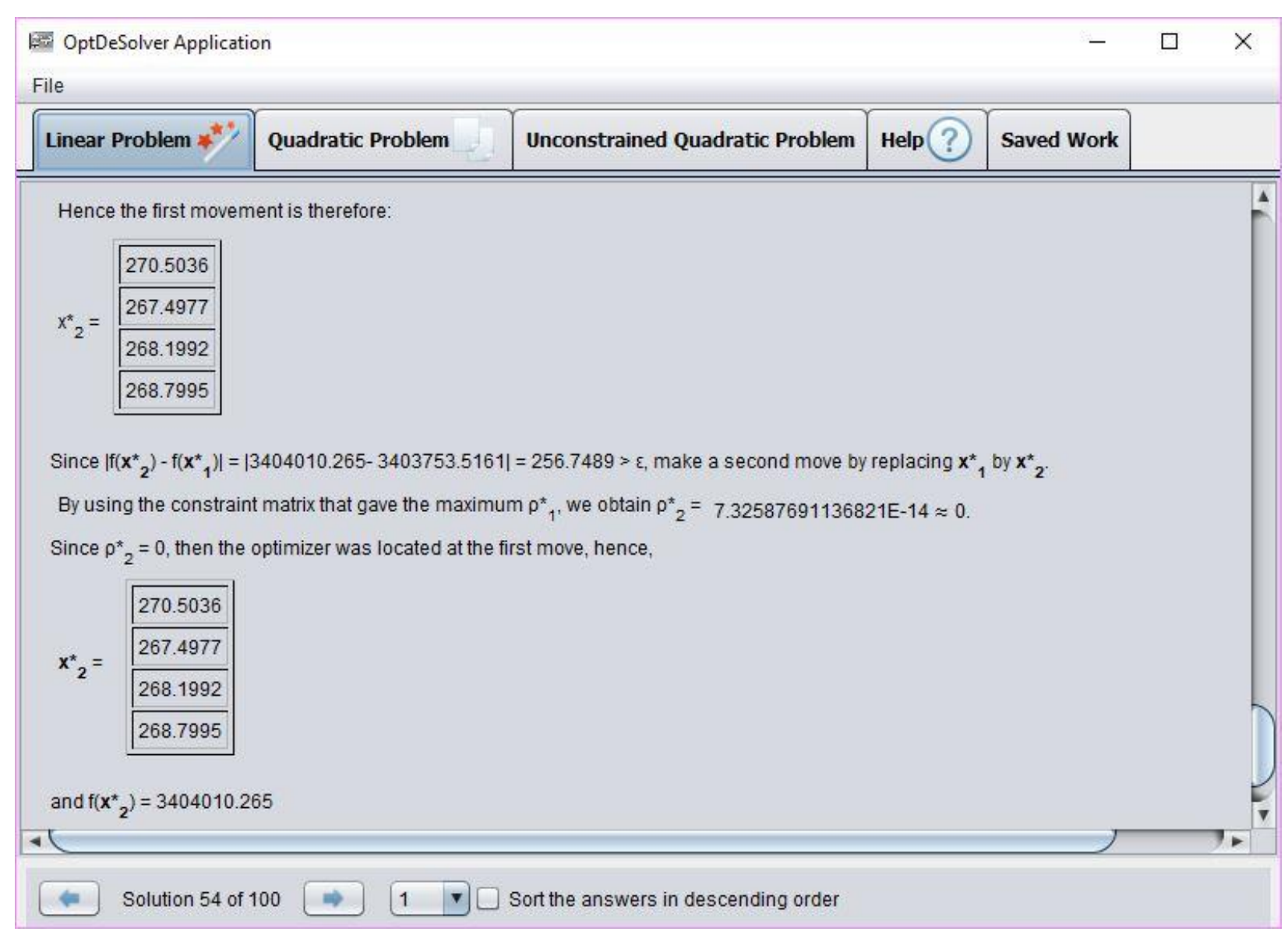

\section{Conclusion}

For the achievement of optimal ingredient allocation and mixing, that is , the best way to allocate ingredient and mixing that result in maximum profit. In this work, we have proposed a mathematical model for the efficient allocation of nine different ingredients such as Flour, Sugar, Oil, Salt, Baking powder, Petit, Marie, Lemon and Chocolate that results in optimal production of four (4) different types of biscuit. The problem of this allocation in the production of biscuit is modeled as a linear programming problem and analyzed using an invariant property based algorithm approach. An Optdesolver, a computer program was used to obtain the optimal solution to this problem. This solution revealed that in order to have a maximum profit of $\$ 3,404,010.27$, the allocations to shortcake, petit, marie and gem should respectively be $\$ 270.50, \$ 267.50, \$ 268.20$ and $\$ 268.80$.

\section{References}

1. (www.bakeinfo.co.nz)

2. (www.ethioembassy.org.uk, www.worldbakers.com/confectionary

3. R. A. McCance etal (1945) " The Chemical Composition of Wheat and Rye of Flours Derived Therefrom" Department of Medicine, Cambrige.

4. Abhyuday Techno Economics Consultant Private Limited 211-212, Patel Avenue Nr Gurudwara, Gujarat, India (agrofood@abhyuday.in)

5. Lain Davidson (2017) " Biscuit Baking Process: A Guide to Good Quality Biscuit" www.biscuitpeople.com

6. B. A. Robin (1954) "Formular, Dough Mixing Method: Review of Literature" Oregon State University

7. Mustafa Ozilgen and J.R Heil (1994) 'Mathematical Modelling of Transcient Heat and Mass Transport in Baking Biscuit' Journal of Food Processing and Preservation, volume8, Issue 2 pages 133- 148

8. Inyama, S. C, ( 2007): Operation Research; An Introduction, Supreme Publishers, N0. 47 Okigwe Road, Owerri, Nigeria. 
9. Etukudo, Idorenyin and Umoren, Mfoniso (2014): Invariant Property Based Algorithm for Solving Linear Programming Problems, International Journal of Scientific and Engineering Research, Volume 5, Issue 9, 945 - 950, ISSN 2229-5518.

10. Sharma, S.D 2010

11. Winston, W.L (1994); Operations Research: Applications and Algorithms, third reverse and enlarge edition.

12. Taha, H. A (2005);Operation Research; An Introduction

13. Stenby Andresen, M., Loje and Adlier-Nissen, J. (2013), Experimentally Supported Mathematical Modeling of Continuous Baking Processes, Kgs. Lyngby; Technical University of Denmark (DTU)

14. Zavvar Sabegh et al (2016), A Mathematical Model and Optimization of Total Production Cost and Quality of a deteriorating Production cogentMathematics(2016),3:1264175,http://dx.doi.org/10.1080/23311835.2016.1264175 